\title{
Cholera toxin inhibits human hepatocarcinoma cell proliferation in vitro via suppressing ATX/LPA axis
}

\author{
Qi XIA ${ }^{1, \#}$, An-mei DENG ${ }^{2, \#}$, Shan-shan $W^{1}$, Min ZHENG ${ }^{1, *}$ \\ ${ }^{1}$ State Key Laboratory of Infectious Disease Diagnosis and Treatment, First Affiliated Hospital, College of Medicine, Zhejiang University, \\ Hangzhou 310003, China; ${ }^{2}$ Laboratory Diagnostics, Shanghai Changzheng Hospital, Shanghai 200003, China
}

\begin{abstract}
Aim: To investigate the antitumor effect of cholera toxin (CT) in hepatocellular carcinoma (HCC) in vitro and the mechanisms underlying the effect.

Methods: Human hepatocellular carcinoma cell lines Hep3B and Huh7, which expressed moderate and high level of autotaxin (ATX), respectively, were used. Cytokine level in the cells was evaluated using ELISA assay, and cell proliferation was investigated using MTT assay. ATX expression was determined using Western blot. ATX/lyso-PLD activity in the conditioned medium was measured using FS-3, a fluorescent lysophosphatidylcholine (LPC) analogue, as substrate.

Results: Exposure to CT (7.5 and $10 \mathrm{ng} / \mathrm{mL})$ significantly inhibited the cell growth, decreased secretion of proinflammatory cytokine TNF- $\alpha$ and promoted secretion of anti-inflammatory cytokines IL-4 and IL-10. CT at $10 \mathrm{ng} / \mathrm{mL}$ markedly suppressed ATX expression in Hep3B and Huh7 cells. Furthermore, ATX and lysophosphatidic acid (LPA) were found to be crucial for growth of the cancer cells. CT could inhibit TNF- $\alpha$-induced expression and secretion of ATX that led to decreased activity of lysophospholipase D, thus decreasing the conversion of LPC to LPA.

Conclusion: CT inhibits hepatocellular carcinoma cell growth in vitro via regulating the ATX-LPA pathway.
\end{abstract}

Keywords: cholera toxin; hepatocarcinoma; autotaxin; lysophosphatidic acid; cell proliferation

Acta Pharmacologica Sinica (2011) 32: 1055-1062; doi: 10.1038/aps.2011.31; published online 18 Jul 2011

\section{Introduction}

Hepatocellular carcinoma (HCC) is the third most common cause of cancer-related death worldwide ${ }^{[1,2]}$. The increasing incidence and poor prognosis of hepatocellular carcinoma ${ }^{[3]}$ emphasize a need to develop effective chemoprevention for this disease. In recent years, many biological factors with potential prognostic significance for HCC have been associated with the invasiveness, metastasis, recurrence, and survival of $\mathrm{HCC}^{[4]}$.

Autotaxin (ATX), discovered in human melanoma cells, was identified as a gene with enhanced mRNA expression in human hepatitis associated $\mathrm{HCC}^{[5]}$. ATX was initially characterized as an autocrine motility factor found in conditioned medium from A2058 melanoma cells ${ }^{[6]}$. Since then, it has been shown that ATX is an important mediator of tumorigenesis that stimulates angiogenesis, survival, growth, migration, and invasion of tumor cells ${ }^{[7-9]}$. The impact of ATX on cancer biol-

\footnotetext{
\# These authors contributed equally to this work.

* To whom correspondence should be addressed.

E-mail minzheng@zju.edu.cn

Received 2010-11-15 Accepted 2011-03-18
}

ogy is mostly due to its intrinsic lysophospholipase activity, through which it hydrolyzes lysophosphatidylcholine (LPC) into lysophosphatidic acid (LPA). ATX plays an important role in inflammation related liver tumorigenesis, and aberrant ATX expression may lead to altered LPC/LPA balance and thus changes in their receptor-mediated functions, resulting in enhanced tumor progression ${ }^{[10]}$.

LPA acts through the G-protein coupled EDG (endothelial differentiation gene) receptors to modulate cell motility. EDG receptor signal transduction is associated with a number of physiologic and pathophysiological effects. In the context of cancer, the pathophysiological effects of LPA include stress fiber formation, membrane ruffling, and lamellipodia formation ${ }^{[9]}$, which have been linked to the malignant phenotype.

Cholera toxin (CT) is the major virulent factor of Vibrio cholerae and is the most recognizable enterotoxin causing diarrhea, second only to cardiovascular disease as a cause of death ${ }^{[11]}$. It is known to bind with high affinity to monosialoganglioside (GM) on the cell surface and stimulate ADP-ribosylation of the stimulating $\mathrm{G}$ protein of adenylate cyclase, G stimulatory, resulting in accumulation of cellular $\mathrm{CAMP}^{[12,13]}$. CT has been 
reported to modulate cellular function, including modification of cell growth. For example, CT stimulates the growth of cultured human mammary epithelial cells ${ }^{[14]}$ and epithelial cells from normal human bronchus ${ }^{[15]}$ in the presence of serum or growth factors. In contrast, it has also been shown that CT influences the proliferation of hormone-dependent rat mammary cancer cells ${ }^{[16]}$ and human small-cell lung cancer cells ${ }^{[17]}$. Although the mechanism behind CT-induced cellular events is not definitively known at present, it is believed that increased intracellular cAMP is a participating element. However, Viallet $e t$ al have reported that elevation of cellular cAMP alone could not account for CT-induced growth inhibition of human small-cell lung cancer ${ }^{[17]}$. Moreover, the effect of CT on hepatocellular carcinoma remains unclear.

In this study, we examined the direct anti-proliferative effects of CT on the human hepatocellular carcinoma cell lines, Hep3B and Huh7, and the indirect effects of CT on cell growth, through regulation of proinflammatory cytokine secretion and the ATX/LPA axis in HCC cells.

\section{Materials and methods Reagents}

CT was purchased from Sigma Chemical Co (St Louis, MO, USA). The polyclonal antibody against ATX was generated in rabbits as previously described ${ }^{[18]}$. ATX activity assay reagents were from Echelon Biosciences, Inc (Salt lake City, UT, USA). Fatty acid-free bovine serum albumin (BSA) was from Calbiochem-Novabiochem Co (San Diego, CA, USA). LPC (1-oleoyl) was obtained from Avanti Polar Lipids, Inc (Alabaster, AL, USA). Ki16425 was from Cayman Chemical (Ann Arbor, MI, USA).

\section{Cell lines and cell culture}

The human hepatocarcinoma cell line Hep3B was purchased from ATCC (HB-8064 $\left.{ }^{\mathrm{TM}}\right)$. The human hepatoma Huh-7 cell line was purchased from Japanese Collection of Research Bioresources (Tokyo, Japan; JCRB0403). All cells were cultured in Dulbecco's modified Eagle's medium (DMEM; SigmaAldrich, St Louis, Mo, USA) supplemented with 10\% ( $v / v)$ fetal bovine serum (FBS) (JRH Biosciences, Lenexa, KS, USA). All cultured cells were incubated at $37^{\circ} \mathrm{C}$ in a humidified atmosphere containing $5 \% \mathrm{CO}_{2}$. Cells were serum-starved overnight and then treated with CT. Total RNA was extracted or cell lysate was prepared after stimulation for the indicated time.

\section{Proliferation assay}

Cell proliferation was evaluated by 3-(4,5-dimethylthiazol2-yl)-2,5-diphenyl tetrazolium bromide (MTT) assay. Cells were seeded at a density of $5 \times 10^{3}$ cells per well in 96-well plates, and the cells were treated with reagents at different concentrations for $72 \mathrm{~h}$. Four hours prior to reading the plates, MTT was added under sterile conditions, and the cells were returned to the incubator. After incubation, the plates were read in an enzyme-linked immunosorbent assay (ELISA) plate reader at absorbance measurements of $570 \mathrm{~nm}$. Each experi- ment was performed in six replicate wells and independently repeated four times.

$\left[{ }^{3} \mathrm{H}\right]-\mathrm{TdR}$ incorporation in Hep3B or Huh7 cells was performed in 96-well microtiter plates. After $48 \mathrm{~h}$ in culture, 1 pCi of $\left[6-{ }^{3} \mathrm{H}\right]$ thymidine (Amersham, Buckinghamshire, UK) was added for $6 \mathrm{~h}$. At the end of the incubation period, cells were procured on filters, and the incorporated radioactivity was counted.

\section{siRNA transfection}

The human hepatocarcinoma cell lines Hep3B or Huh7 were plated on 6-cm dishes. Sixteen hours later, siRNAs (final concentration of $3 \mathrm{nmol} / \mathrm{L}$ ) were added to the cells using an RNAiMAX reagent (Invitrogen, Carlsbad, CA, USA) according to the manufacturer's instructions, and the cells were further cultured for $24 \mathrm{~h}$. The ATX messenger RNA (mRNA) level was measured using real-time TaqMan technology. A cell proliferation assay was performed after $24 \mathrm{~h}$ of serum starvation, as described previously. The siRNAs for ATX (siATX, L-019059), LPA (siLPA $\left._{1}, \mathrm{~L}-003656\right), \mathrm{LPA}_{2}\left(\mathrm{siLPA}_{2}\right.$, L-004602), $\mathrm{LPA}_{3}\left(\mathrm{siLPA}_{3}, \mathrm{~L}-004895\right)$, and non-silencing RNA (NS, D-001810-10) were obtained from Dharmacon (Lafayette, CO, USA).

\section{Quantitative real time RT-PCR (qRT-PCR)}

Total RNA was isolated from cells using the RNeasy kit, following the manufacturer's instructions (QIAGEN, Valencia, CA, USA). Total RNA $(2 \mu \mathrm{g})$ was reverse-transcribed in a total reaction volume of $20 \mu \mathrm{L}$ using the high capacity cDNA reverse transcriptase kit (Applied Biosystems, Foster City, CA, USA) as described by the manufacturer. Single stranded cDNA products were then analyzed by real-time PCR using standard commercially available TaqMan probes for ATX (Hs00196470_m1). The amount of target gene was normalized to the internal standard 18S rRNA (Hs99999901_s1) and reported as a relative value.

\section{Cytokine concentration assay}

Cytokine concentrations were determined using commercially available enzyme-linked immunosorbent assay (ELISA) kits. TNF- $a$, IL-4, and IL-10 secretion from Hep3B and Huh7 cells was determined by studies to measure their biological activity and by an ELISA assay. To measure the biological activity of these cytokines, Hep3B and Huh7 cells were plated at a concentration of $5 \times 10^{3}$ cells/well in 96-well plates, and the cells were treated with $\mathrm{CT}$ at different concentrations. After $12 \mathrm{~h}$ of incubation, TNF- $\alpha$, IL-4, and IL-10 levels were determined by Quantikine high-sensitivity ELISA kits (R\&D Systems; Minneapolis, MN, USA), which were used according to the manufacturer's instructions.

\section{Preparation of conditioned media and cell lysates and immuno-} blot analysis

Conditioned media were prepared by incubating $80 \%$ confluent cells in dishes for $24 \mathrm{~h}$ in serum-free DMEM containing $0.1 \%$ fatty acid-free BSA. Media were harvested, clarified 
by centrifugation, and filtered through a $0.22-\mu \mathrm{m}$ filter. The media were concentrated by Amicon Ultra-15 Centrifugal Filter Units before being used for immunoblot analysis. At the same time, total cell lysates were prepared from cell monolayers incubated in RIPA buffer $[50 \mathrm{mmol} / \mathrm{L}$ Tris- $\mathrm{HCl}, \mathrm{pH}$ 7.4; $150 \mathrm{mmol} / \mathrm{L} \mathrm{NaCl} ; 2 \mathrm{mmol} / \mathrm{L}$ EDTA, $1 \mathrm{mmol} / \mathrm{L}$ sodium orthovanadate, 1\% Nonidet P40; 1\% sodium deoxycholate; $0.1 \%$ sodium dodecylsulfate (SDS), $2 \mathrm{mmol} / \mathrm{L}$ phenylmethylsulfonyl fluoride (PMSF), and protease inhibitor cocktail]. Fifteen micrograms of total cellular protein was resolved by SDSPAGE. Blots were probed with appropriate antibodies. Anti$\beta$-actin was used as a loading control.

\section{ATX/lyso-PLD activity assay}

The conditioned serum-free medium from Hep3B and Huh7 cells stimulated with reagents was concentrated (40-fold) using Amicon Ultra 50000 (Millipore). DMEM without cells was used as a control. ATX/lyso-PLD activity in concentrated conditioned medium was analyzed using the fluorogenic substrate FS-3 according to the manufacturer's protocol. Briefly, $10 \mu \mathrm{L}$ concentrated medium was mixed with $5 \mu \mathrm{mol} / \mathrm{L}$ FS-3 and assayed in a 96-well plate. Changes in fluorescent intensity were measured with a SpectraMax Gemini EM Fluorescence Microplate Reader (Molecular Devices, Sunnyvale, CA, USA) with excitation and emission wavelengths of 485 and $525 \mathrm{~nm}$, respectively.

\section{Lipid extraction and analysis}

Lipids were extracted from conditioned media and analyzed using LC-MS (API-4000, Applied Biosystems) ${ }^{[18,19]}$. Briefly, conditioned media were incubated with $15 \mu \mathrm{mol} / \mathrm{L}$ LPC for $3 \mathrm{~h}$ at $37^{\circ} \mathrm{C}$. Samples $(1.3 \mathrm{~mL})$ were mixed with $3 \mathrm{~mL}$ of $\mathrm{MeOH} /$ chloroform (2:1) following the addition of $10 \mu \mathrm{L}$ of LPA $(1 \mu \mathrm{mol} / \mathrm{L})$ as an internal standard and $10 \mu \mathrm{L}$ of $\mathrm{HCl}(6$ $\mathrm{mol} / \mathrm{L})$. The samples were vortexed for $1 \mathrm{~min}$ and incubated on ice for $10 \mathrm{~min}$. Chloroform $(1 \mathrm{~mL})$ and PBS $(1 \times)(0.5 \mathrm{~mL})$ were added to separate the phases, and samples were vortexed for $1 \mathrm{~min}$ prior to centrifugation $(1750 \times \mathrm{g}$ for $10 \mathrm{~min}$, at $\left.10^{\circ} \mathrm{C}\right)$. The lower phase was transferred to a new glass tube. The upper phase was re-extracted using $2 \mathrm{~mL}$ chloroform and combined with the lower phase. After the solvent was evaporated under nitrogen at room temperature, the dried lipids were re-extracted using $2 \mathrm{~mL}$ chloroform and combined with the lower phase. After evaporating the solvent under nitrogen at room temperature, the dried lipids were re-suspended in $100 \mu \mathrm{L}$ of $\mathrm{MeOH}$ and $10 \mu \mathrm{L}$ of sample, respectively, and subsequently used for mass spectrometry (MS) analyses. Typical operating parameters for MS were as follows: nebulizing gas (NEB) 15, curtain gas (CUR) 8, collision-activated dissociation (CAD) gas 35, electro-spray voltage 5000 with positive-ion MRM mode, and a heater temperature of $500{ }^{\circ} \mathrm{C}$. Precursor mode 153 was set as the daughter ions of LPA. The dwell time in the MRM mode was $75 \mathrm{~ms}$. A TARGA C18 $5 \mu \mathrm{mol} / \mathrm{L}$, $2.1 \mathrm{~mm}$ id $\times 10 \mathrm{~mm}$ TR-0121-C185 (Higgins Analytical, Southborough, MA, USA) HPLC column was used for the separa- tion of different phospholipids and for the detection of LPAs. The mobile phase $\mathrm{A}$ was $\mathrm{MeOH} /$ water/ $\mathrm{NH}_{4} \mathrm{OH}$ (90:10:0.1, $v / v / v)$. The HPLC separations were performed at $12 \mathrm{~min} /$ sample using the following scheme: 1) 100\% A for 3 min with a flow rate of $0.2 \mathrm{~mL} / \mathrm{min}$; 2) the mobile phase was changed from $100 \%$ A to $100 \%$ B for 2 min with a flow rate from 0.2 to $0.8 \mathrm{~mL} / \mathrm{min}$; 3) a constant flow rate of $0.8 \mathrm{~mL} / \mathrm{min}$ for $5 \mathrm{~min}$; 4) the mobile phase was changed from $100 \%$ B to $100 \%$ A for 1 min with a flow rate from 0.8 to $0.2 \mathrm{~mL} / \mathrm{min}$; and 5) a constant flow rate of $0.2 \mathrm{~mL} / \mathrm{min}$ for $1 \mathrm{~min}$.

\section{Statistical analysis}

All data are presented as mean $\pm S D$. Statistical significance between two groups was determined by Student's $t$ test. $P$ values of $<0.05$ were considered statistically significant.

\section{Results}

Inhibition of Hep3B and Huh7 cell proliferation by CT

To examine the effect of CT on proliferation of Hep3B and Huh7 cells, three doses of CT were tested. As shown in Figure 1, CT dose-dependently inhibited cell growth in both cell lines significantly. The inhibitory effect of CT was most pronounced in Hep3B cells (approximately 80\% growth inhibition at the highest CT dose tested) but was also strong in Huh7 cells (approximately 70\% growth inhibition at the highest CT dose tested).
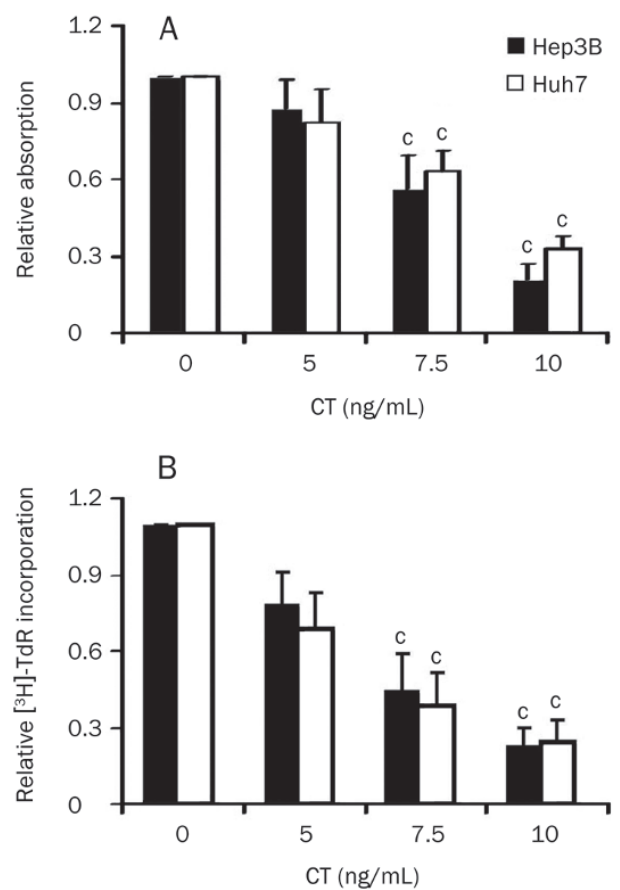

Figure 1. Effect of CT on cell proliferation of Hep3B and Huh7 cells. Hep3B or Huh7 cells were treated with the indicated doses of CT. Cells were grown for $72 \mathrm{~h}$, and cell growth was measured with (A) MTT staining and $(B)\left[{ }^{3} \mathrm{H}\right]-\mathrm{TdR}$ incorporation. Data are expressed as mean $\pm \mathrm{SD}$ of four independent experiments. ${ }^{\circ} P<0.01$ compared with untreated cells (control) (paired Student's $t$ test). 
CT decreases production of the pro-inflammatory cytokine TNF- $\alpha$ and increases production of the anti-inflammatory cytokines IL-4 and IL-10 in Hep3B and Huh7 cells

To evaluate the effect of CT on the production of inflammatory cytokines, we measured TNF-a production as a pro-inflammatory marker and IL-4 and IL-10 protein production as anti-inflammatory markers by ELISA in Hep3B and Huh7 cells. The addition of CT significantly inhibited TNF-a production in both Hep3B and Huh7 cells in a dose-dependent manner, with approximately $50 \%$ inhibition compared with the control at the highest CT dose tested (Figure 2A). In contrast, CT significantly increased IL-4 protein production (approximately 2.5fold compared with the control at the highest CT dose tested) and IL-10 protein production (approximately 3-fold compared with the control at the highest CT dose tested) in both Hep3B and Huh7 cells (Figure 2B and 2C).
CT decreased ATX expression and secretion in Hep3B and Huh7 cells

The expression of ATX is regulated by growth factors and cytokines. For example, fibroblast growth factor (FGF) and epidermal growth factor (EGF) have been shown to induce ATX expression, whereas certain cytokines, such as interleukin-4 (IL-4) and interferon-gamma (IFN-ү), decrease the expression of ATX mRNA in cultured fibroblast-like synoviocytes (SFC) ${ }^{[20]}$, while TNF- $\alpha$ increases the expression of ATX mRNA in HCC cells ${ }^{[10]}$. Also, inflammatory cytokines are known to be associated with the inflammation related to liver diseases $^{[21]}$. Here, we examined the effect of CT on the expression of ATX in human liver cell lines. As assessed by qRTPCR assays, CT treatment decreased ATX mRNA levels more than $70 \%$ and $80 \%$, at the highest CT dose tested, in Hep3B and Huh7 cells, respectively (Figure 3D). The inhibitory effect
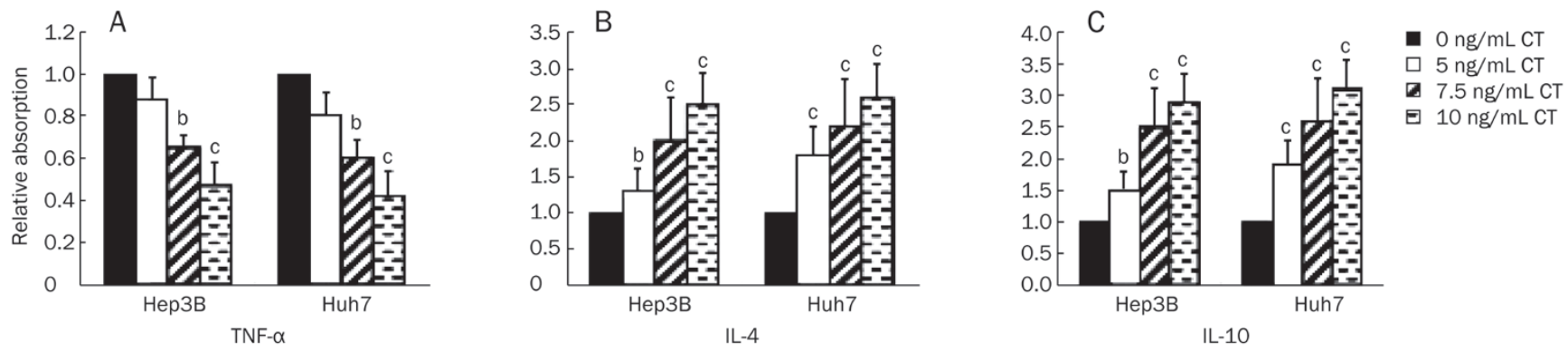

Figure 2. Effects of CT on cytokine secretion. CT reduced secretion of the pro-inflammatory cytokine TNF- $\alpha$ (A) and increased secretion of the antiinflammatory cytokines IL-4 (B) and IL-10 (C). Levels of TNF- $\alpha / \mathrm{IL}-4 / \mathrm{IL}-10$ in cell culture medium were measured by ELISA kits after cells were treated with $\mathrm{CT}$ at doses of $0,5,7.5$, and $10 \mathrm{ng} / \mathrm{mL}$ for $12 \mathrm{~h}$. Data are expressed as mean $\pm \mathrm{SD}$ of four independent experiments. ${ }^{\mathrm{b}} P<0.05,{ }^{\mathrm{c}} P<0.01 \mathrm{compared}$ with untreated cells (control) (paired Student's $t$ test).
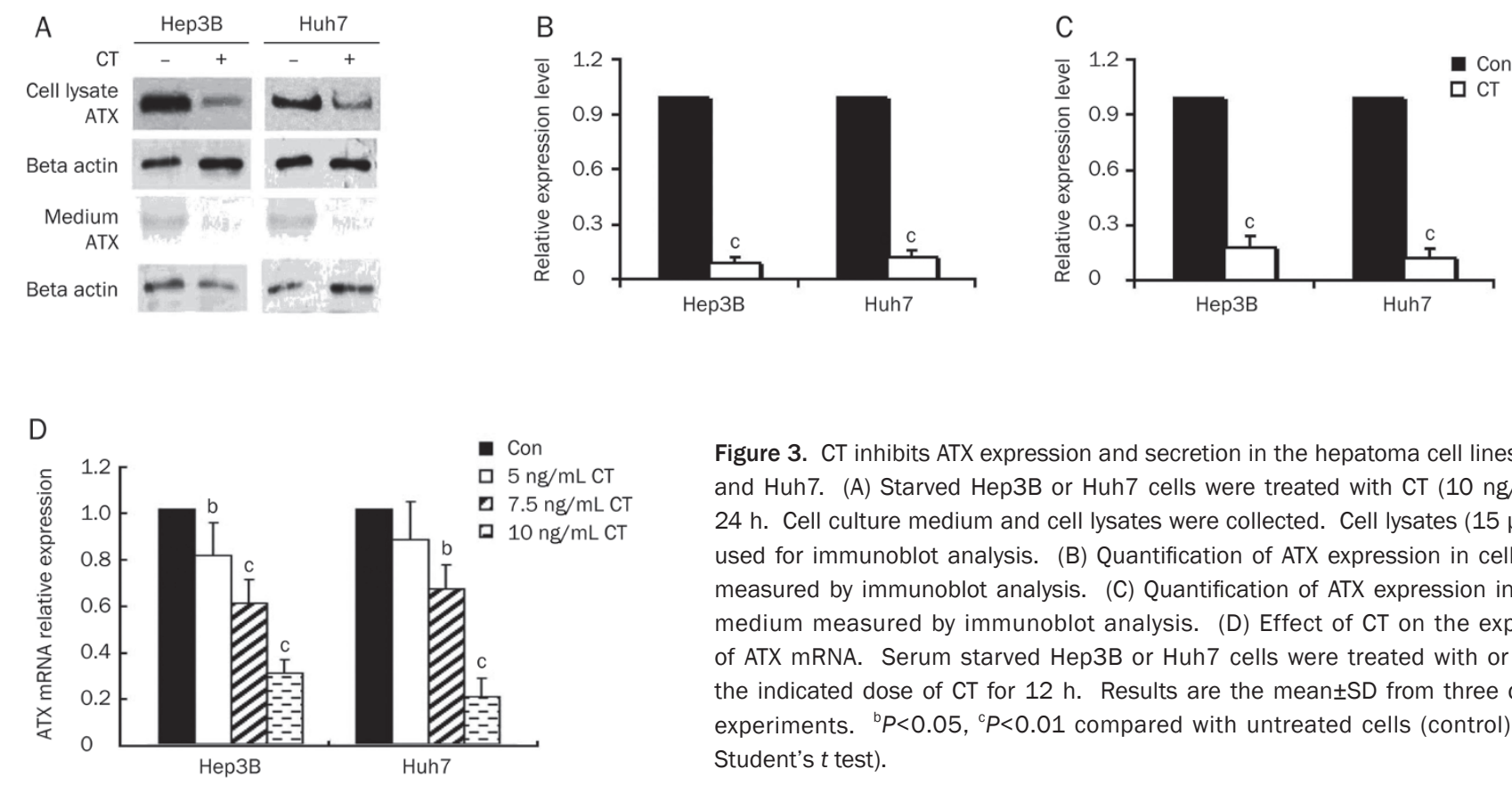

Figure 3. CT inhibits ATX expression and secretion in the hepatoma cell lines Hep3B and Huh7. (A) Starved Hep3B or Huh7 cells were treated with CT $(10 \mathrm{ng} / \mathrm{mL})$ for $24 \mathrm{~h}$. Cell culture medium and cell lysates were collected. Cell lysates (15 $\mu \mathrm{g})$ were used for immunoblot analysis. (B) Quantification of ATX expression in cell lysates measured by immunoblot analysis. (C) Quantification of ATX expression in culture medium measured by immunoblot analysis. (D) Effect of CT on the expression of ATX mRNA. Serum starved Hep3B or Huh7 cells were treated with or without the indicated dose of $C T$ for $12 \mathrm{~h}$. Results are the mean $\pm S D$ from three qRT-PCR experiments. ${ }^{b} P<0.05,{ }^{c} P<0.01$ compared with untreated cells (control) (paired Student's $t$ test). 
of CT on cellular and secreted ATX protein expression was further demonstrated by immunoblot analyses (Figure 3A-3C).

\section{ATX is crucial for Hep3B and Huh7 cells proliferation}

To determine the relationship between the observed in vitro decrease in ATX levels and inhibition of cell proliferation by CT, we investigated the role of ATX in tumorigenic growth of the human hepatocellular carcinoma cell lines Hep3B and Huh7. As shown in Figure 4, CT significantly inhibited IL-4 induced cell proliferation and also decreased ATX expression in cell lysate. Moreover, knockdown of ATX in Hep3B and Huh7 cells had an anti-proliferative effect, as measured by MTT.

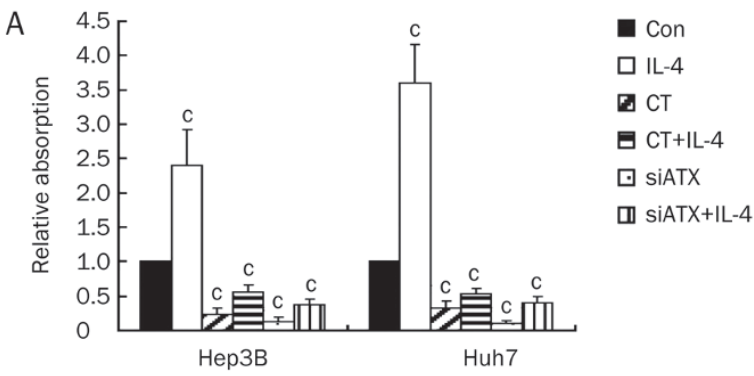

B
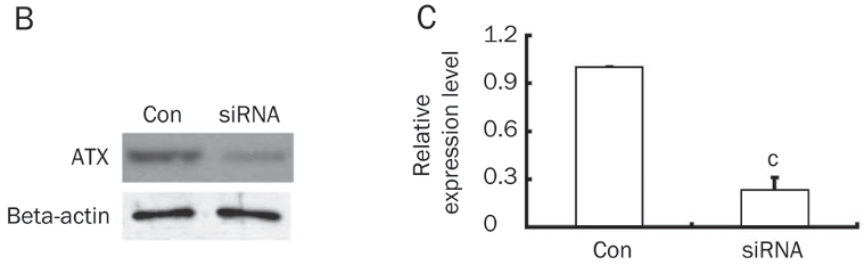

Figure 4. ATX is crucial for Hep3B and Huh7 cells proliferation. (A) Hep3B or Huh7 cells were treated with IL-4 $(10 \mathrm{ng} / \mathrm{mL}), C T(10 \mathrm{ng} / \mathrm{mL}), \mathrm{IL}-4$ (10 ng/mL) plus CT (10 ng/mL), ATX siRNA, or ATX siRNA plus IL-4 (10 $\mathrm{ng} / \mathrm{mL}$ ). Cells were grown for $48 \mathrm{~h}$, and cell survival was measured with MTT staining. (B) ATX was knocked down by treatment of siRNA against ATX. Expression of ATX was assessed by Western blot. (C) Quantification of ATX expression in Hep3B cells treated with siRNA against ATX. Data are expressed as mean $\pm S D$ of four independent experiments. ${ }^{c} P<0.01$ compared with untreated cells (control) (paired Student's $t$ test).

Down-regulation of ATX induced by CT is associated with decreased lyso-PLD activity and conversion of LPC into LPA

Being an enzyme with lyso-PLD activity, ATX plays a critical role in LPA production ${ }^{[22]}$. To explore whether changes in ATX expression induced by CT led to a corresponding decrease in ATX/lyso-PLD activity, we collected conditioned medium at different time points from Hep3B and Huh7 cells that were treated with TNF-a, CT, both TNF- $\alpha$ and $\mathrm{CT}$, or control (0.1\% BSA/PBS). ATX/lyso-PLD activity in conditioned medium was measured using the fluorescent
LPC analogue FS-3 as substrate ${ }^{[23]}$. After TNF-a stimulation, Hep3B and Huh7 cells exhibited about a 1.5-fold and 0.5-fold increase in secreted lyso-PLD activity, respectively (Figure $5 \mathrm{~A}$ and $5 \mathrm{~B}$ ), indicating that TNF-a was able to increase lysoPLD activity in culture medium by inducing ATX expression. Conversely, both cell lines treated with CT exhibited about a 5-fold decrease in secreted lyso-PLD activity compared with control and about a 2-fold and 3-fold decrease in secreted lysoPLD activity induced by TNF-a, indicating that CT was able
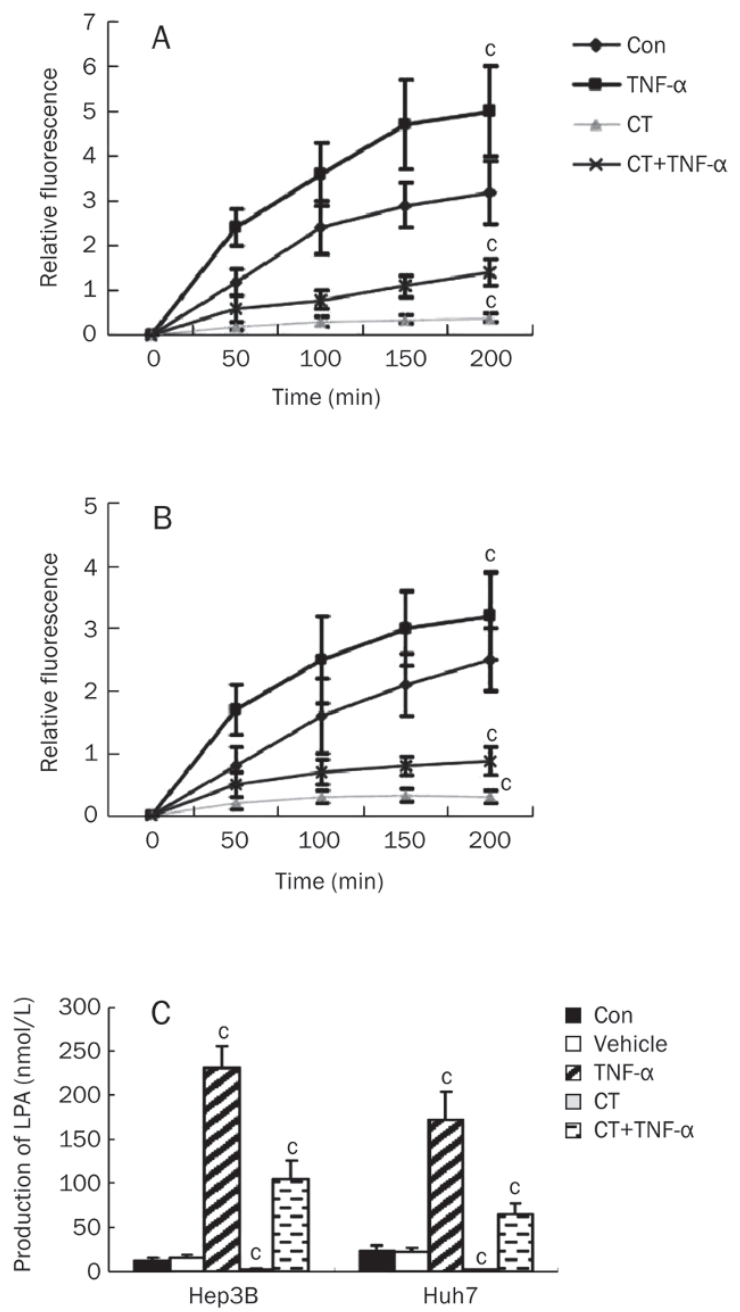

Figure 5. Down-regulation of ATX induced by CT is associated with decreased lysophospholipase D (Iyso-PLD) activity, as indicated by conversion of LPC into LPA, in Hep3B and Huh7 cells. Serum starved Hep3B or Huh7 cells were treated with TNF- $\alpha$ (10 ng/mL), vehicle $(0.1 \%$ BSA/PBS), CT (10 ng/mL) or CT (10 ng/mL) plus TNF- $\alpha$ (10 ng/mL) for $24 \mathrm{~h}$. Hep3B (A) or Huh7 (B) cell medium from different time points were concentrated (40-fold) and assayed for ATX activity using the FS-3 compound. Results are shown as the average relative fluorescence activity $\pm S D$ from three experiments. (C) Cell medium was incubated with $15 \mu \mathrm{mol} / \mathrm{L} \mathrm{LPC}$ for $3 \mathrm{~h}$ at $37^{\circ} \mathrm{C}$. Lipids were analyzed by liquid chromatography-mass spectrometry (LC-MS). Results show the level of LPA from three experiments and are presented as mean \pm SD of four independent experiments. ${ }^{c} P<0.01$ compared with untreated cells (control) (paired Student's $t$ test). 
to decrease lyso-PLD activity in culture medium by inhibiting ATX expression. We next examined LPA production by incubating the conditioned medium from Hep3B or Huh7 cells with $15 \mu \mathrm{mol} / \mathrm{L}$ LPC, a lyso-PLD substrate, followed by liquid chromatography/mass spectrometry (LC-MS) analysis. After supplying the cells with ATX substrate (LPC), LPA levels in the conditioned medium of Hep3B cells treated with vehicle, TNF- $\alpha$ or CT were detected. TNF- $\alpha$ treatment further elevated LPA levels by more than 10-fold, while CT treatment totally inhibited LPA levels in the medium. Also, CT significantly inhibited TNF-a mediated induction of LPA levels. A similar effect was observed in Huh7 cells, where TNF-a treatment induced an approximately 10-fold increase of LPA generation (Figure 5C). Thus, our results demonstrated that secreted ATX from Hep3B or Huh7 cells has lyso-PLD activity and that TNF- $\alpha$ induces ATX expression, secretion, and lyso-PLD activity, resulting in increased extracellular production of LPA from LPC. However, CT treatment had the opposite effect.

\section{LPA is crucial for Hep3B and Huh7 cells proliferation via LPA} receptor 1

Finally, we examined the role of LPA receptors in proliferation of Hep3B and Huh7 cells. For this purpose, we treated cells with Ki16425, an $\mathrm{LPA}_{1}$ and $\mathrm{LPA}_{3}$ antagonist, or siLPA , siLPA $_{2}$, or siLPA $\mathrm{A}_{3}$, cell viability was assessed by MTT assay. As shown in Figure 6, Ki16425 inhibited cell growth in both cell lines in the presence of LPC $(1 \mu \mathrm{mol} / \mathrm{L})$. Furthermore, expression levels of the LPA receptors were altered when cells were transfected with siLPA $A_{1}$, targeting $\mathrm{LPA}_{1}$; siLPA ${ }_{2}$, targeting $\mathrm{LPA}_{2}$; or siLPA $A_{3}$, targeting $\mathrm{LPA}_{3}$, in the presence of LPC (1 $\mu \mathrm{mol} / \mathrm{L})$. Expression of LPA receptors in Hep3B cells was shown in Figure 6A. Results from MTT assays showed that knockdown of $\mathrm{LPA}_{1}$ in Hep3B and Huh7 cells played a role in the anti-proliferative effects of LPA (Figure 6). Therefore, $\mathrm{LPA}_{1}$ plays a critical role in HCC cell proliferation.

\section{Discussion}

The experiments presented here demonstrate that CT is an inhibitor of cell growth in two human hepatocarcinoma cell lines, Hep3B and Huh7. A low dose of CT $(7.5 \mathrm{ng} / \mathrm{mL})$ was effective in Hep3B and Huh7, while CT inhibits the growth of small-cell lung cancers with an $\mathrm{IC}_{50}$ of $27-242 \mathrm{ng} / \mathrm{mL}^{[17]}$. The difference in sensitivity to $\mathrm{CT}$ between the cell types may be explained by differences in expression of cellular binding sites for CT or different levels of ATX, which plays an important role in liver tumorigenesis.

Cytokines play a major role in promoting the growth and metastatic spread of cancer cells. To evaluate the effect of CT on production of pro-inflammatory and anti-inflammatory cytokines, we measured the protein levels of tumor necrosis factor (TNF)- $a$, interleukin-4 (IL-4) and interleukin-10 (IL-10) in Hep3B and Huh7 cells. TNF-a secretion was suppressed by the addition of $\mathrm{CT}$, but, on the contrary, secretion of the antiinflammatory cytokines IL-4 and IL-10 was increased upon treatment with CT.

ATX is overexpressed in various cancers and promotes
A
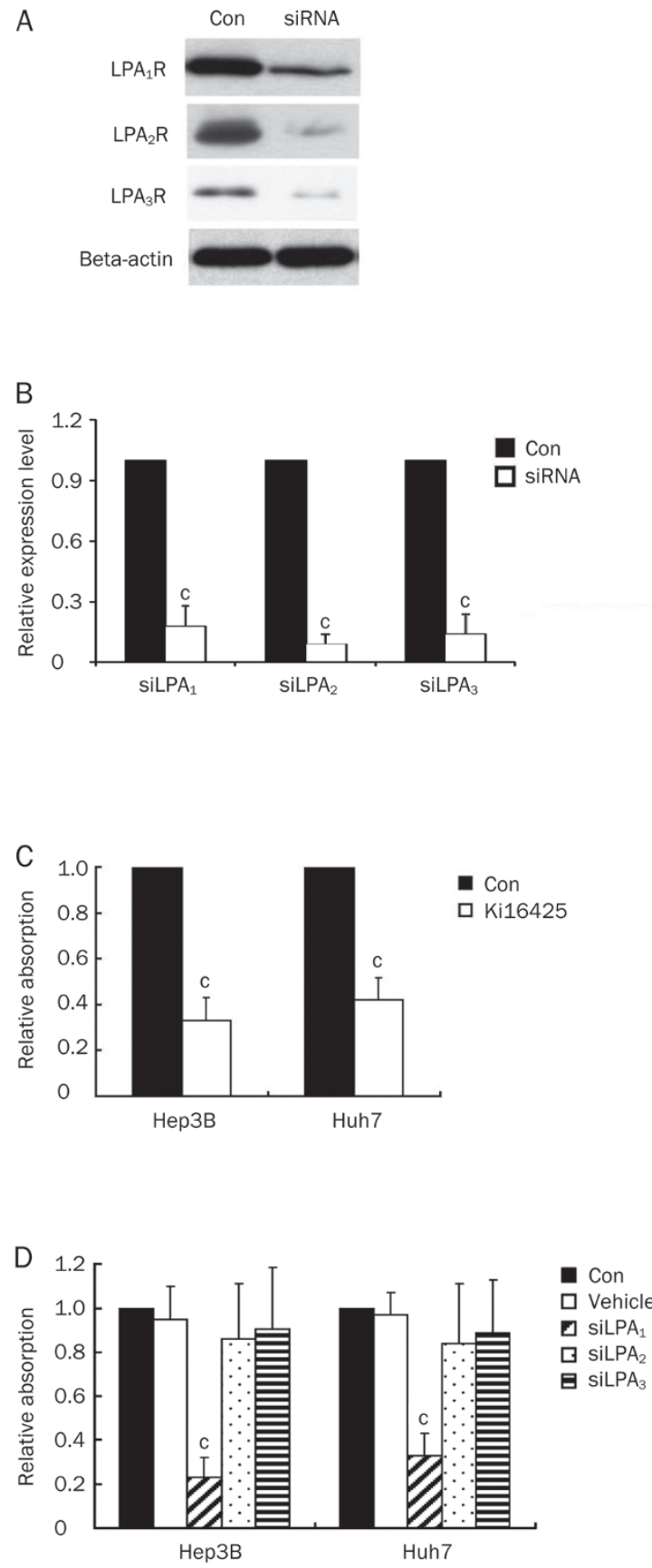

Figure 6. $\mathrm{LPA}_{1}$ is crucial for $\mathrm{HCC}$ cell proliferation. (A) Knockdown of LPA using siLPA 1, siLPA $_{2}$, siLPA $_{3}$. Knockdown efficiency was shown by Western blot analysis. (B) Quantification of Western blot results. (C) Hep3B or Huh7 cells were treated with Ki16425 as described in "Materials and methods". Cell survival was evaluated by MTT assay. (D) Hep3B or Huh7 cells were treated with siRNA against $\mathrm{LPA}_{1}$ receptor $\left(\mathrm{siLPA}_{1}\right), \mathrm{LPA}_{2}$ receptor $\left(\mathrm{siLP}_{2}\right)$ or $\mathrm{LPA}_{3}$ receptor $\left(\mathrm{SiLPA}_{3}\right)$ as described in "Materials and methods". Non-silencing RNA (Vehicle) was transfected as vehicle. Cell survival was evaluated by MTT assay. Data are expressed as mean \pm SD of four independent experiments. ${ }^{c} P<0.01$ compared with untreated cells (control) (paired Student's $t$ test).

tumor progression by stimulating angiogenesis, tumor cell survival, growth, migration, and invasion ${ }^{[24-26]}$. TNF-a has 
been reported to promote ATX secretion in both Hep3B and Huh7 cell lines, and chronic inflammation has been associated with the development of liver cancer, which is consistent with evidence that ATX expression levels are well correlated with the derivative origins of HCC cell lines related to inflammation $^{[10]}$. In our study, we showed that treatment of Hep3B and Huh7 cells with CT inhibits ATX expression at both the RNA and the protein level. Furthermore, knockdown of ATX resulted in complete loss of the effect of CT on proliferation, suggesting ATX is crucial for the proliferation of liver cancer cells. Meanwhile, CT significantly inhibited TNF-a production in both Hep3B and Huh7 cells in a dose-dependent manner, suggesting CT might repress ATX expression by reduction of TNF-a production. This reduction in TNF-a secretion indicates that CT treatment leads to less chronic inflammation in HCC, suggesting that CT inhibits HCC proliferation by relieving chronic inflammation.

Moreover, as ATX is an enzyme with lyso-PLD activity, the aberrant expression of ATX has the potential to alter the delicate balance between LPA and LPC signaling. Therefore, we examined PLD activity and production of LPA from LPC in Hep3B and Huh7 cells treated with CT and TNF-a. TNF-a, a pro-inflammatory cytokine, promoted ATX secretion and LPA production in both cell lines. In contrast, CT significantly inhibited ATX secretion and LPA production. Moreover, secretion of enzymatically active ATX promoted Hep3B and Huh7 cell proliferation, which is dependent on extracellular LPC concentration and can be demonstrated to be a direct effect of increased LPA levels. Therefore, the expression of LPA is also crucial for the proliferation of HCC cells. Using an $\mathrm{LPA}_{1}$ and $\mathrm{LPA}_{3}$ specific antagonist ${ }^{[27]}$ (Ki16425), LPA ${ }_{1}$ specific small interfering RNA (siLPA 1$), \mathrm{LPA}_{2}$-specific small interfering RNA (siLPA ${ }_{2}$ ), and $\mathrm{LPA}_{3}$-specific small interfering RNA ( $\left(\mathrm{LPA}_{3}\right.$ ) in proliferation assays, we conclude that the $\mathrm{LPA}_{1}$ receptor plays the main role in the proliferation of HCC cells. Recently, Park et al also determined the involvement of $\mathrm{LPA}_{1}$ receptor activation by LPA produced by ATX activity in HCC invasion and metastasis, which suggests these could be novel biomarkers and potential therapeutic targets for $\mathrm{HCC}^{[28]}$. Despite data demonstrating the association of ATX and LPA with invasion and metastasis of HCC, whether CT inhibits HCC proliferation by interfering with LPA production is unknown. Accumulating evidence showing that the LPA/ ATX axis regulates cancer cell proliferation, survival, and invasion suggests that LPA and its analogs, LPA receptors and ATX, are potential therapeutic targets for cancer treatment. Our results show that CT inhibits HCC progression by reducing $\mathrm{LPA}_{1}$ production and ATX secretion. This suggests HCC proliferation could be inhibited by treatment with $\mathrm{CT}$ and that $\mathrm{CT}$ is a promising biological molecular for the treatment of liver cancer in patients.

Taken together, this is the first characterization of the mechanism by which $\mathrm{CT}$, through regulation of ATX, influences HCC cells. CT inhibited proliferation of two human hepatocarcinoma cell lines, Hep3B and Huh7, by suppressing the ATX/LPA axis.

\section{Acknowledgements}

The work was supported by the State S\&T Projects (11th Five Year) (2008ZX10002-007), the National Natural Science Foundation of China (№ 30772017 and 30972730), and the Qianjiang Talent Project of Zhejiang Province (2010R10081).

\section{Author contributions}

Qi XIA performed cell culture, MTT experiments, and the ATX/lyso-PLD activity assay. An-mei DENG performed the ELISA assay and lipid extraction and analysis. Shan-shan WU performed the knock down and qRT-PCR assays. Min ZHENG conceived the study and guided the biochemical experiments.

\section{References}

1 Parkin DM, Bray F, Ferlay J, Pisani P. Global cancer statistics, 2002. CA Cancer J Clin 2005; 55: 74-108.

2 Shariff MI, Cox IJ, Gomaa Al, Khan SA, Gedroyc W, Taylor-Robinson SD. Hepatocellular carcinoma: current trends in worldwide epidemiology, risk factors, diagnosis and therapeutics. Expert Rev Gastroenterol Hepatol 2009; 3: 353-67.

3 Greten TF, Korangy F, Manns MP, Malek NP. Molecular therapy for the treatment of hepatocellular carcinoma. Br J Cancer 2009; 100: 19-23.

4 Braicu C, Burz C, Berindan-Neagoe I, Balacescu O, Graur F, Cristea $\mathrm{V}$, et al. Hepatocellular carcinoma: tumorigenesis and prediction markers. Gastroenterol Res 2009; 2: 191-9.

5 Cooper AB, Wu J, Lu D, Maluccio MA. Is autotaxin (ENPP2) the link between hepatitis $C$ and hepatocellular cancer? J Gastrointest Surg 2007; 11: 1628-34.

6 Stracke ML, Krutzsch HC, Unsworth EJ, Arestad A, Cioce V, Schiffmann $\mathrm{E}$, et al. Identification, purification, and partial sequence analysis of autotaxin, a novel motility-stimulating protein. J Biol Chem 1992; 267: 2524-9.

7 Kishi Y, Okudaira S, Tanaka M, Hama K, Shida D, Kitayama J, et al. Autotaxin is overexpressed in glioblastoma multiforme and contributes to cell motility of glioblastoma by converting lysophosphatidylcholine to lysophosphatidic acid. J Biol Chem 2006; 281: 17492-500.

8 Black EJ, Clair T, Delrow J, Neiman P, Gillespie DA. Microarray analysis identifies Autotaxin, a tumour cell motility and angiogenic factor with Iysophospholipase D activity, as a specific target of cell transformation by v-Jun. Oncogene 2004; 23: 2357-66.

9 Hama K, Aoki J, Fukaya M, Kishi Y, Sakai T, Suzuki R, et al. Lysophosphatidic acid and autotaxin stimulate cell motility of neoplastic and non-neoplastic cells through LPA ${ }_{1}$. J Biol Chem 2004; 279: 17634-9.

$10 \mathrm{Wu} J \mathrm{M}, \mathrm{Xu} \mathrm{Y}$, Skill NJ, Sheng H, Zhao Z, Yu M, et al. Autotaxin expression and its connection with the TNF-alpha-NF-kappaB axis in human hepatocellular carcinoma. Mol Cancer; 2010; 9: 71.

11 Goodman L, Segreti J. Infectious diarrhea. Dis Mon 1999; 45: 26899.

12 Holmgren J. Actions of cholera toxin and the prevention and treatment of cholera. Nature 1981; 292: 413-17.

13 Guerrant RL, Fang GD, Thielman NM, Fonteles MC. Role of platelet activating factor in the intestinal epithelial secretory and Chinese hamster ovary cell cytoskeletal responses to cholera toxin. Proc Natl Acad Sci U S A 1994; 91: 9655-8.

14 Taylor-Papadimitriou J, Purkis P, Fentiman IS. Cholera toxin and analogues of cyclic AMP stimulate the growth of cultured human mammary epithelial cells. J Cell Physiol 1980; 102: 317-21. 
15 Lechner JF, Haugen A, Autrup H, McClendon IA, Trump BF, Harris CC. Clonal growth of epithelial cells from normal adult human bronchus. Cancer Res 1981; 41: 2294-304.

16 Cho-Chung YS, Clair T, Shepheard C, Berghoffer B. Arrest of hormonedependent mammary cancer growth in vivo and in vitro by cholera toxin. Cancer Res 1983; 43: 1473-6.

17 Viallet J, Sharoni Y, Frucht H, Jensen RT, Minna JD, Sausville EA. Cholera toxin inhibits signal transduction by several mitogens and the in vitro growth of human small-cell lung cancer. J Clin Invest 1990; 86: 1904-12.

18 Xiao Y, Chen Y, Kennedy AW, Belinson J, Xu Y. Evaluation of plasma lysophospholipids for diagnostic significance using electrospray ionization mass spectrometry (ESI-MS) analyses. Ann N Y Acad Sci 2000; 905: 242-59.

19 Zhao Z, Xiao Y, Elson P, Tan H, Plummer SJ, Berk M, et al. Plasma lysophosphatidylcholine levels: potential biomarkers for colorectal cancer. J Clin Oncol 2007; 25: 2696-701.

20 Kehlen A, Lauterbach R, Santos AN, Thiele K, Kabisch U, Weber E, et al. IL-1 beta- and IL-4-induced down-regulation of autotaxin mRNA and PC-1 in fibroblast-like synoviocytes of patients with rheumatoid arthritis (RA). Clin Exp Immunol 2001; 123: 147-54.

21 Wullaert A, van Loo G, Heyninck K, Beyaert R. Hepatic tumor necrosis factor signaling and nuclear factor-kappaB: effects on liver homeo- stasis and beyond. Endocr Rev 2007; 28: 365-86.

22 Umezu-Goto M, Kishi Y, Taira A, Hama K, Dohmae N, Takio K, et al. Autotaxin has lysophospholipase $D$ activity leading to tumor cell growth and motility by lysophosphatidic acid production. J Cell Biol 2002; 158: 227-33.

23 Morris AJ, Smyth SS. Measurement of autotaxin/lysophospholipase D activity. Methods Enzymol 2007; 434: 89-104.

24 Lee HY, Clair T, Mulvaney PT, Woodhouse EC, Aznavoorian S, Liotta LA, et al. Stimulation of tumor cell motility linked to phosphodiesterase catalytic site of autotaxin. J Biol Chem 1996; 271: 24408-12.

25 Nam SW, Clair T, Campo CK, Lee HY, Liotta LA, Stracke ML. Autotaxin (ATX), a potent tumor motogen, augments invasive and metastatic potential of ras-transformed cells. Oncogene 2000; 19: 241-7.

26 Nam SW, Clair T, Kim YS, McMarlin A, Schiffmann E, Liotta LA, et al. Autotaxin (NPP-2), a metastasis-enhancing motogen, is an angiogenic factor. Cancer Res 2001; 61: 6938-44.

27 Ohta H, Sato K, Murata N, Damirin A, Malchinkhuu E, Kon J, et al. Ki16425, a subtype-selective antagonist for EDG-family lysophosphatidic acid receptors. Mol Pharmacol 2003; 64: 994-1005.

28 Park SY, Jeong KJ, Panupinthu N, Yu S, Lee J, Han JW, et al. Lysophosphatidic acid augments human hepatocellular carcinoma cell invasion through $\mathrm{LPA}_{1}$ receptor and MMP-9 expression. Oncogene 2011; 30: 1351-9. 